\title{
"There's no reason to do monogamy": Evidence for and Characteristics Associated with a Strong Desire for Consensual Nonmonogamy
}

\author{
Jennifer Arter $^{1}$ (D) Sacha S. Bunge ${ }^{1}$
}

Accepted: 5 November 2021

(c) The Author(s) 2021

\begin{abstract}
Introduction Consensual nonmonogamy (CNM) is a form of relationship practiced by many despite widespread stigma against it. In this study, we explore evidence of strong, persistent desire for CNM among some individuals, and look for commonalities among these individuals.

Method Between February 2019 and June 2020, we conducted qualitative, semi-structured interviews with 51 US adults who had practiced CNM for between 3 and 50 years, recruited via community contacts and snowball method. Participants reported a broad diversity of sexual orientations and gender identities; $62.7 \%$ reported European/white ancestry. We conducted thematic analysis to examine evidence of strong, persistent desire for CNM and common characteristics and experiences among participants.

Results We describe 7 sub-themes that suggest a strong desire for CNM, such as pursuing CNM early in life, experiencing difficulties in attempts at monogamy, and describing one's desire for CNM as enduring or unchangeable. We then describe 9 characteristics and experiences that were common among participants, such as a preference for autonomy, not experiencing categorical distinctions among relationships, desiring to make life plans with multiple adults, and exposure to communities whose norms do not assume monogamy.

Conclusions Our data indicate a pattern of desires, life choices, and self-perceptions suggesting that some individuals strongly desire and persistently pursue CNM (whereas others appear to be comfortable with both CNM and monogamy).

Policy Implications Our results suggest that some individuals consistently desire and pursue CNM relationships, and therefore would benefit from efforts toward destigmatization and reduction of institutional disadvantage against the practice of CNM.
\end{abstract}

Keywords Consensual nonmonogamy $\cdot$ Polyamory $\cdot$ Orientation $\cdot$ Romantic relationships $\cdot$ Sexual minorities

\section{Introduction}

Consensual nonmonogamy (CNM; Conley et al., 2013) is an increasingly visible practice among US adults (Barker, 2005; Ritchie, 2010). Qualitative research suggests that CNM relationships are often stable over long periods and that individuals in CNM relationships generally view their relationship practices and outcomes in positive ways (e.g., Barker, 2005; Barker \& Ritchie, 2007; Cohen, 2015; de Visser \& McDonald, 2007; Klesse, 2011; Sheff, 2016). There are also indications that CNM is associated with happiness, life satisfaction, and relationship satisfaction on par with monogamous relationship

Jennifer Arter

1 Psychology Department, San Francisco State University, 1600 Holloway Avenue, San Francisco, CA 94132, USA practices (Conley et al., 2017; Parsons et al., 2012; Fairbrother et al., 2019; Fleckenstein \& Cox, 2015; Moors et al., 2017a; Morrison et al., 2013; Rubel \& Bogaert, 2015) and that CNM is associated with some specific positive outcomes such as a greater likelihood of safer-sex practices (Conley et al., 2012; Lehmiller, 2015).

There is an increasing body of evidence showing that, within countries such as the USA in which monogamy is the norm, CNM is nevertheless practiced among a percentage of individuals that is at least comparable to the percentage of individuals in such countries who identify on the LGBTQ2S + spectrum (Haupert et al., 2017; Levine et al., 2018; Moors et al., 2021; Rubin et al., 2014). And yet stigma against CNM remains widespread in the USA and other such countries; CNM relationships are often perceived as being low quality, less committed, or even immoral, and those who practice them are perceived as being less desirable as social 
contacts (Balzarini et al., 2018b; Boyd, 2017; Conley et al., 2013; Hutzler et al., 2016; Klesse, 2005; Moors et al., 2013; Rodrigues et al., 2018). And this stigma is felt by those who practice CNM; Cohen (2015) reported that many individuals in open relationships described dealing with social stigma as the most negative part of being in an open relationship. The fact that this relationship practice persists among sizable numbers of people despite the disadvantages associated with widespread stigma against it suggests that for some individuals, it would be quite difficult or aversive to adhere to monogamy. If this is the case, then documenting such a possibility, along with the experiences, self-perceptions, and characteristics of such individuals, would be an important way to lay groundwork in efforts toward reduction of stigma and prejudice.

There has as yet been little research that can address such aims. Studies examining individuals' interest in CNM have often focused on openness toward or willingness to engage in CNM among individuals who may or may not have actually practiced it, and have often relied on broad quantitative measures (see Sizemore \& Olmstead, 2017, for a review). Such studies have suggested that openness to CNM is associated with the personality traits of openness to experience (positively) and conscientiousness (negatively; Moors et al., 2017b) as well as with greater openness toward casual sex (Ka et al., 2020) and a rejection of monogamous ideals (Sizemore \& Olmstead, 2018). This work is valuable, but it does not directly address the motivations or characteristics of those who are strongly drawn to CNM.

Investigations into the characteristics and motivations of those who do practice CNM have recently become more prevalent; one consistent finding is an association between identification as LGBTQ2S + and engagement in CNM, which holds regardless of other demographic characteristics (Balzarini et al., 2018a; Haupert et al., 2017; Levine et al., 2018; Moors et al., 2021; Rubin et al., 2014; St. Vil et al., 2021). Motivations for engaging in CNM among those who practice it have also been found to include a desire for variety, excitement, and exploration (both sexual and non-sexual); a desire for autonomy in actions and relationship choices; seeking of growth-inducing and self-expanding activities; diversity in one's sources of need-fulfillment; and enhancement of a relationship via formation of other relationships or sexual connections (Cohen, 2015; O’Byrne \& Haines, 2019; Moors et al., 2017a; St. Vil et al., 2021; Wood et al., 2021). These groundbreaking studies have begun to illuminate in detail the motivations and desires of those who practice CNM, and the results of some of these studies hint at the idea that some individuals consider CNM to be "natural" for themselves. For example, Wood et al. (2021) note that some participants described CNM as "authentic" or "natural" for themselves or even as a "relationship orientation," although these striking responses are collected as a sub-theme under the theme of "autonomy" and are not further highlighted by the authors. St. Vil et al. (2021) also note that some participants described CNM as "natural" for themselves, and Cohen (2015) reports that some participants described that the best feature of being CNM is that it is "honest." Such statements are striking. More detailed exploration of the self-perceptions and life choices of individuals who make such statements might reveal a strong and persistent interest in CNM, which would make an important contribution to understanding why CNM is practiced even in the face of stigma, as well as providing an important impetus for combating such stigma.

In the current study, we will explore the experiences, selfperceptions, and characteristics of a group of individuals who have practiced CNM, with two goals: to explore evidence of strong and persistent desire for CNM among these individuals, and to examine common characteristics and experiences reported by these individuals. We note that these aims intersect with a conversation in the literature regarding whether CNM should be considered something akin to an "orientation," and the pros and cons of such a designation (Aviram, 2010; Barker \& Langdridge, 2010; Heckert, 2010; Klesse, 2014; Tweedy, 2011; Willey, 2010). While we acknowledge the complexities attached to the label "orientation" and the importance of this conversation, our intent is not to delve into this discussion but rather to document the life choices and self-perceptions of a group of individuals who practice CNM.

\section{Method}

\section{Procedure}

Qualitative data for this paper were taken from semi-structured interviews conducted as part of a larger study on how CNM individuals relate to metamours (those with whom they share a romantic partner). This research was reviewed and approved by the Institutional Review Board of San Francisco State University (Protocol Number H18-20 and renewal H18-20R1), and was carried out in accordance with the ethical standards laid down in the Belmont Report. The convenience sample of participants was recruited between February 2019 and June 2020 via snowball method. Specifically, the first author began recruiting via personal contacts in local nonmonogamous/ polyamorous communities, and each participant was asked to forward the study invitation to others. Participants were not recruited via any particular social organization or online community. The original aim in recruiting was to find individuals with substantive experience interacting with metamours; we did not recruit with the aim of finding individuals who self-identified or were behaviorally defined as having a strong desire for CNM. Thus, requirements for participation included at least 5 years of experience in CNM relationships, as well as 
having at least one relevant metamour experience (i.e., the participant had gotten to know at least one metamour, or had had at least two partners who had gotten to know each other). However, in four cases, participants with fewer than 5 years' experience were included in the sample, because they had extensive metamour experience. All participants gave informed consent, including consent to specific uses of their recorded interviews, before any data were collected. Interviews lasted between 48 and $109 \mathrm{~min}$ and were conducted in person or by phone or Zoom. All interviews were conducted by the first author. Participants were asked a set of demographic questions, followed by a set of opening questions. They were then given a list of topics related to metamour relationships, which were created based on personal experiences of the first author and informal conversations with others, and included feelings about metamours, communication with metamours, meeting and spending time with metamours, privacy/information-sharing, calendaring and time management, difficult situations, and dating metamours. Participants chose which of these topics they preferred to talk about, and were asked questions in those topic areas; the interviews proceeded in a semi-structured fashion, and participants were encouraged at the outset to follow their own train of thought (see, e.g., Giorgi, 2012; Polkinghorne, 1989). Data in the current paper are drawn from throughout these interviews, whenever participants made relevant statements. Such statements often appeared in responses to two of the opening questions: "Briefly, how did you come to be nonmonogamous/polyamorous?" and "What do you like about nonmonogamy/polyamory, what do you get out of it?" However, relevant statements also arose spontaneously in many other parts of the interviews, and the two questions above did not always yield information relevant to the current study. ${ }^{1}$

\section{Participants}

Fifty-one participants took part in this study. Average age reported by participants was 37.1 years $(S D=9.6)$, with three participants declining to report their age. Participants reported between 3 and 50 years' experience in CNM; many participants gave estimates or ranges in response to this question and thus it is not possible to report a valid average,

\footnotetext{
${ }^{1}$ Because the topic of the current paper arose in the course of initial data analysis and was not one that we set out to investigate, the many questions that happened to yield relevant statements are heterogenous and unrelated to the current study. For example: "Do you have specific vocabulary, ways that you like to refer to your partners, your partners' partners, other terms I should use while we're talking?" (yielding relevant statements from four participants); "Do you prefer to know if and when you're going to run into a metamour?" (yielding relevant statements from two participants); or "All other things being equal, how well would you prefer to know a metamour?" (yielding relevant statements from four participants).
}

but 32 participants reported 10 or more years of experience. See Table 1 for other demographic characteristics.

Participants were not asked to label the type of CNM they practiced, but most were asked if they had particular terms that they preferred the interviewer to use when referring to their practice during the interview. Many did not have a strong preference; 14 stated explicitly that they had no preference, 11 stated that poly or polyamorous worked or was "fine," 1 stated that nonmonogamous was "fine," and 2 stated that they did not like or identify with any labels. Others did have preferences; 9 stated that they preferred poly or polyamorous, 6 stated that they preferred nonmonogamous, and 1 stated that they preferred relationship anarchist; 7 were not asked about their preferred terminology. No participants chose the term "swinger," and no participants' descriptions of their relationship practices were aligned with the practices often described using this term (i.e., extra-dyadic sexual activity in the context of emotionally exclusive dyadic relationships; Balzarini et al., 2020; de Visser \& McDonald, 2007).

\section{Analysis}

Transcription, data organization, and reflexive thematic analysis were completed by the first author (Bazeley \& Jackson, 2013; Braun \& Clarke, 2021; Saldaña, 2013).

Table 1 Demographic characteristics of participants

\begin{tabular}{llr}
\hline Characteristic & $n$ & $\%$ \\
\hline "How would you describe your ethnic and/or racial identity?" & \\
White/European ancestries & 32 & 62.8 \\
Black/African American ancestries & 7 & 13.7 \\
Asian ancestries & 4 & 7.8 \\
Latinx ancestries & 4 & 7.8 \\
Mixed/other ancestries & 4 & 7.8 \\
"How would you describe your gender identity?" & & \\
Nonbinary/genderqueer/other non-cisgendered & & \\
Woman/female & 28 & 54.9 \\
Cisgendered woman & 9 & 17.7 \\
Man/male & 9 & 17.7 \\
Cisgendered man & 2 & 3.9 \\
Decline to respond & 2 & 3.9 \\
"How would you describe your sexual orientation?" & 1 & 1.9 \\
Bisexual/pansexual/omnisexual/queer & & \\
Mostly heterosexual & 35 & 68.6 \\
Gay/lesbian/homosexual & 7 & 13.7 \\
Straight/heterosexual & 4 & 7.8 \\
Other & 3 & 5.9 \\
Decline to respond & 1 & 1.9 \\
\hline
\end{tabular}

Percentages do not always add to 100 due to rounding

ae.g., "meh," "?"

be.g., "heteroflexible," "95\% straight," "Kinsey 2" 
Interviews were transcribed and organized using Transana Basic, version 3.21. Transcription, concurrent with a firstpass analysis, began immediately upon collection of the first interviews, such that thematic elements arising from early interviews informed the interviewer's perspective in later interviews (Corbin \& Strauss, 1990; Saldaña, 2013). Interviews were not transcribed in the same sequence in which they were collected, but rather in an intuitively chosen sequence aimed at maximizing movement between contrasting types of experiences among participants (Bazeley \& Jackson, 2013; Saldaña, 2013); specifically, while transcribing and conducting a first-pass analysis of a given interview, the researcher would be reminded of things that other interviewees had said, and would choose the next interview to transcribe based on an intuition that it would provide an informative contrast regarding a particular emerging topic of interest. This method allowed the researcher to develop emerging ideas and themes more effectively. Interviews were transcribed verbatim, omitting proper nouns and details that might identify participants, as well as extraneous dysfluencies and repeated words. Nearly all of the text of each interview (omitting interruptions and off-topic conversation) was categorized, often into multiple topic areas (Bazeley \& Jackson, 2013), with the aim of cataloging all thematic elements in this wide-ranging data set (Braun \& Clarke, 2006; Saldaña, 2013). These categories sometimes described explicit opinions or practices named by participants, and sometimes attempted to describe latent, underlying patterns identified by the researcher within participants' described behaviors, opinions, and self-perceptions (Braun \& Clarke, 2006).

A large set of thematic categories and analytic notes were created, organizing text segments into many evolving topic areas (Bazeley \& Jackson, 2013; Braun \& Clarke, 2006; Corbin \& Strauss, 1990; Saldaña, 2013). These emergent categories were iteratively refined, grouped under larger themes, and split into sub-themes as more data were added (Bazeley \& Jackson, 2013; Corbin $\&$ Strauss, 1990). The topic of the current paper was one of several that arose in the course of this first-pass analysis. Once all data had been examined in the first pass, all data relevant to the current paper were reexamined as a set, with the following goals: refining and expanding the themes and sub-themes to exhaustively explore the relevant data; examining the set of quotes within each sub-theme to more precisely define each one, including returning to interview transcripts to examine quotes in context; iteratively splitting, combining, and reorganizing emerging sub-themes and their sub-elements to most closely capture the apparent nature of a given set of quotes; examining similarities and differences among subthemes, to look for patterns of associations; and developing higher-order thematic concepts and the relationships between these concepts via reflection, interpretation, and description (Bazeley, 2009; Bazeley \& Jackson, 2013; Corbin \& Strauss, 1990; Saldaña, 2013). The first author worked independently, but consulted with the second author throughout regarding the process of constructing meanings from the themes; disagreements in this process were resolved via discussion (Bazeley, 2009; Bazeley \& Jackson, 2013; Corbin \& Strauss, 1990; Saldaña, 2013).

Finally, because we are interested in evidence regarding a strong and persistent desire for CNM, but our sample was not initially recruited with this aim in mind (i.e., we did not recruit participants who self-selected or were in some way behaviorally defined as having a "strong or persistent desire for CNM," nor did we ask participants systematically about this topic), we provide basic quantitative evidence regarding the numbers of participants whose statements are represented in the themes (Bazeley, 2009; Bazeley \& Jackson, 2013; and see, e.g., Sizemore \& Olmstead, 2018; St. Vil et al., 2021, for similar reporting). Bazeley (2009) notes that it is sometimes important to place themes in context in terms of how widely they are represented in the data, as well as who is not represented in the themes (i.e., "negative cases or outliers"; Bazeley, 2009, p. 12). Given the nature of our sample in relation to the aims of this paper, providing this context for our results is valuable.

\section{Results}

\section{Theme 1: Evidence Suggesting a Strong and Persistent Desire for CNM}

The responses of many participants in this sample suggest an early, consistent, and enduring interest in or desire for nonmonogamous relationships. This interest was manifested in several specific ways, as follows.

1. Early pursuit of CNM relationships $(n=26)$. Many participants described having pursued or engaged in CNM starting with very early dating experiences $(n=11)$; others more specifically described having "invented" CNM early on in spite of having had little exposure to the idea, sometimes on their own $(n=3)$ but more often in collaboration with one or more partners $(n=8)$; and some described having been introduced to CNM by a partner early in life and quickly deciding that it was comfortable or "right" for themselves $(n=4)$.

(Interviewer: If you could briefly tell me how you came to be poly?) I don't really know. It was sort of like, it was when I started having relationships with 
people, when I was a teenager. I kind of, I started that way. I feel like, as you do, like you're in baby relationships as a teenager, and tend to like date lots of people simultaneously, or at least I did. And I never got into a monogamous relationship. I had people who wanted to, I just never wanted to be in one. So it wasn't really something that I came to find, it was just something that I just was doing. And then I started to learn more about, oh, that's like a way people have relationships, and I haven't really even considered it before. (Interviewer: Interesting, so you were just kind of doing it by default.) By default. (Interviewer: On your own.) Uh-huh. (21)

I was (age: teenager), the person I was dating was interested in other people, and had called me and was really sad, and was like, I think that we should break up, and (I said) what if we just both saw other people, 'cause we care about each other and we love each other a lot? And he was like, is that a thing that people do? It's like, I don't know; we can try it. And so that's how it started. (Interviewer: Ok, and then you just stuck with that after that?) Yeah, yeah. I've been in one monogamous relationship, and it was terrible. (17)

Well in high school I was dating a lady, you know, a person in the same high school as me... And she used the words free love, kind of like, you date people and you all love each other and it's great, and very like hippie style, and I was like, yes, this is right, this is correct. And that wasn't the very first time I'd ever dated anyone, but it was definitely formative. And so you know, I dated her and I dated her girlfriend and we all dated this collection of people, and it was great.... And none of us knew this was a thing in the world. Like I didn't think about whether it was a thing that other people might do. It was just what me and my people were doing. (20)

2. Experiencing nonmonogamous desires despite lack of awareness of CNM $(n=10)$. Some participants described a history of simultaneous attraction to or love for multiple people $(n=5)$, an interest in nonmonogamous experiences $(n=2)$, or discomfort with monogamy $(n=3)$ that arose in the context of monogamous dating before they were aware of the possibility of ethical and consensual nonmonogamy.

(Interviewer: So first question is just, briefly, how did you come to be polyamorous?) I had a guy I was dating introduce me to the concept and it kind of blew my mind, because a couple years before that, I was in love with two people and I didn't know how to man- age that. So I would break up with one and then start dating the other and realize I still loved the other one, I would break up with that one and go back. It was kind of painful. But in (year) I was introduced to the concept, and it changed my life. (41)

I was with a long-term partner, together for like (number of) years at that point. And I was like, basically in love with this (other) guy... And so friends started writing about this (nonmonogamy), I'm like, oh, this is ok. Like, you can, you can actually have multiple relationships. You don't have to be monogamous. (Interviewer: Right. What did you think about that experience before you had heard that? Did you feel like you were doing something wrong or something?) I felt like my feelings were ok... but I thought it was, like, unacceptable to open it up to a physical relationship. (45)

3. Immediate feeling of affinity upon learning about CNM $(n=11)$. Eleven participants talked about their discovery of the concept of CNM as an immediate feeling of recognition of themselves or of what they want in life.

(Interviewer: So briefly, how did you come to be poly?) Ah. For me it, finding this word was like finding the word bisexual. Less of a, oh what a great idea because I am politically and/or ethically and/ or sexually aligned with it, I will embrace this; more like, oh finally, someone $\mathrm{f}^{*}$ cking wrote down how I've always felt, right, like that's how it felt for me.... and my experience of finding the framework and the language was primarily one of relief. (37)

I read the word (polyamory) in a book, and then I did what any good nerd would do, which is google the word I didn't know, and I read the definition of polyamory, and it was like a little light bulb going off in my head, because it, it sort of suddenly gave me insight into a lot of experiences that I had had growing up that could not be explained by the monogamous paradigm that I'd grown up with.... I think I had sort of compartmentalized those experiences and put them in a little box and been like, ok well this is just a weird thing about me. And then I read the definition of polyamory, and it suddenly gave a name to all of those experiences, as like, oh, I am one of a category of people. I am not just a one-off. (29)

4. Unsuccessful attempts to be in monogamous relationships $(n=13)$. Some participants described relationships in which they attempted monogamy and failed by cheating 
on a partner $(n=3)$ or succeeded but were unhappy about the monogamy, such that the relationship either ended $(n=8)$ or became CNM $(n=2)$; one of the cheating incidents also resulted in a transition to a CNM relationship.

I don't know, it's very individual but the people I end up with, in my life, are those people who have like, cheated, ended monogamous relationships just 'cause they were monogamous, which is me, right, like you know, go crazy with just one person. (23)

5. Difficulty remembering or intuiting the feelings or expectations of those who practice monogamy $(n=6)$. Some participants described attempts at monogamous relationships in which they had to work to understand or remember the preferences or sensibilities of monogamous partners, which did not feel natural or intuitive to them $(n=4)$, for example, that one should not comment on the attractiveness of others to one's partner or that various kinds of affectionate or sexual contact with others might not be ok with one's partner. Three participants expressed a more general lack of understanding of why people would expect or desire sexual or emotional exclusivity (one of these made both kinds of statements).

...I did it (nonmonogamy) before in the sense that I was dating someone, and... I made out with, extensively made out with some woman in (city) at (location) and I was really, I was so stoked about it, and when I came back to tell him, he was shocked, and he told me, that's cheating. And I was like, but it didn't feel like cheating. It felt really good. So, like, you mean I can't do that? So that's when I, the gears were grinding, in terms of like, having a relationship and then realizing some people don't like it if I express myself with other people, so something wasn't resonating with me about monogamy, but I didn't really have the terminology for it. (42)

...even just the concept of cheating, to me, seems weird. Like if you meet someone, and they're hot, and you want to have sex with them, have sex with them. Like what does that have to do with your relationship? I don't get it. (24)

6. Continuing interest in CNM in spite of experiencing or observing difficult nonmonogamous situations $(n=19)$. Some participants described how their interest in CNM remained in spite of having experienced or observed relationship difficulties related to nonmonogamy, including struggling with jealousy or other difficult feelings (in oneself or in a partner) in early CNM relationships $(n=7)$, experiencing/observing unethical nonmonogamy (i.e., being cheated on and lied to, $n=5$; or observing cheating in parents' relationships, $n=2$ ), or various other difficult, unsuccessful, or painful situations $(n=5)$.

I really felt like I had to try monogamy, give it a real try. And I did and I failed and I was like, I don't want to do that again.... my parents who were in an open relationship, their open relationship situation wasn't awesome, like it didn't develop into an awesome rapport later in life, so there was definitely some fear inside of me of like, that doesn't work. Yeah. (Interviewer: So you had to experience just hating monogamy.) Yes. Really be like, this really doesn't work, I've tried, I've put my best effort, I really did, I really was the best, people would come over to our house and they'd tell me, they'd be like, you're the perfect girlfriend. Yeah. I really tried. And then I was like, yeah no. (01)

...my first like practical, quote unquote, (nonmonogamous) experience was super fraught, because the person I was dating.... she is not poly.... So that's like, so that relationship, navigating that, of like, being poly but every time I expressed interest in anybody else we would break up for a week, like that was complicated.... But that first experience was definitely like, interestingly, I never questioned whether or not I was poly. I was like no this is, this is very much me, this feels like my skin. (37)

7. Explicitly stating that CNM is an enduring desire or preference $(n=22)$. Many participants made direct statements to the effect that CNM is their enduring or unchangeable preference: some stated that it is something they have always wanted or that has always been true about them $(n=5)$; some stated that they would not want or choose to be monogamous $(n=10)$; some stated that the possibility of multiple relationships is true for them continuously even when they have only one or no partners $(n=7)$; and some stated that nonmonogamy is "natural" to them $(n=1)$, that they simply "are" nonmonogamous $(n=1)$, or that they experience nonmonogamy as an "identity" or "orientation" $(n=3)$. (Three participants made statements fitting into two of these elements and one made statements fitting into three of them. One participant also described this idea with regard to others they know in addition to themselves.)

Ooh, I have never not been poly.... there has never, like there's never actually been a time when I was like, this is the only thing, you know. (19) 
(Interviewer: So just opening up, I'm curious briefly how you came to be nonmonogamous.) I think I was born that way. You know, I really do. I think it's, I've even used that example, like, being gay or something like that. You're just, it's just the way you're wired, you know? (33)

I've never really, as an adult, been interested in monogamy. Although sometimes I'll end up functionally monogamous, as in during a pandemic, but that's not really on purpose. And yeah, that's, I've never really been interested in it. (51)

...I never had a monogamous relationship partner, all of my relationships were nonmonogamous from the start.... And the first one, that was short.... But the second one was about (number of) months long and felt like, with (name), and felt like we were really doing it, you know. And that's when it was like, oh yeah, I will never go, there's no reason to do monogamy. (26)

\section{Summary Regarding Participants Represented in Theme 1}

The large majority of participants appear in at least one of these seven sub-themes: $29.4 \%$ appear once, $33.3 \%$ appear twice, $21.6 \%$ appear three times, $9.8 \%$ appear four or more times, and 5.9\% do not appear at all. (Each participant is counted only once per sub-theme, even when they make statements appearing in more than one element within that sub-theme.) Thus, a substantial portion of our participants are well-represented by this theme: many of them were drawn to CNM immediately upon learning of it (or even invented it for themselves in absence of such exposure), disliked or had difficulty understanding or conforming to monogamy, were undaunted by difficulties in CNM relationships, and/or experienced their own desire for CNM as enduring or unchangeable.

However, some participants' responses did not fit this pattern. As mentioned, three participants (5.9\%) made no statements fitting into any of these sub-themes. It appears that these three participants may have had a less-strong preference for CNM; two of them reported that they were, at the time of the interview, happy in monogamous relationships after having engaged in CNM extensively at other times, and the third reported having transitioned a previously comfortable monogamous relationship to CNM. However, these three were not the only participants who reported sometimes having been comfortable with monogamy. Eight other participants also mentioned having been at least somewhat comfortable in monogamous relationships in the past and a ninth stated that they did not consider themselves "obligate poly." Four of these nine also noted that they consider their own CNM to be a relationship choice and not an "identity." Among these nine participants, four appear once in these sub-themes, four appear twice, and one appears three times.

\section{Theme 2: Other Characteristics Commonly Described by Those with a Desire for CNM}

Theme 1 presented evidence regarding the strength and enduring quality of some individuals' desire for CNM relationships. In theme 2, we explore other characteristics and experiences commonly mentioned by our participants, which we speculate might predispose individuals toward CNM (noting that the current data cannot address the question of causation, and are only suggestive in nature).

1. Broad and frequent attractions to others $(n=7)$. Seven participants described feeling frequent attraction to many people or a desire for close connections with many people.

I think that I'm just inclined to intimacy with lots of people.... I definitely seek out intimacy with my friendships, with my romantic entanglements, with partners. I'm a high-intimacy person, and there's so many different kinds of people that it's hard to imagine picking one. (29)

2. Not experiencing categorical distinctions among close connections $(n=20)$. Many participants described ways in which their feelings for close others do not lend themselves to categorical distinctions: some described that they feel just as intimate or committed in some of their non-sexual relationships as in some of their sexual ones $(n=12)$, some said that their friendships often include sex $(n=3)$, some described how their relationships exist on a "spectrum" of closeness $(n=2)$, and some stated that they dislike rigidly categorizing their relationships or the kinds of intimacy they can have in different relationships $(n=6)$. (Three participants made statements falling into two of these elements.)

I don't draw a huge distinction between partners and friends. So like, my best friends, in a sense, are partners to me. As a matter of fact, are partners to me, not just even "in a sense.".... my best friend (name) definitely feels like a partner to me, definitely is a partner to me. (39)

And I don't know whether my kind of omni, I just, every person is someone that I could love, and therefore someone I could be lovers with, is weird. I don't know if I'm, you know, I mean lots and lots of people that I've talked to about it are like, oh I'm not usually lovers with my friends. And I'm like, why not? (40)

3. Feeling that one person cannot or should not meet all of another's relational needs $(n=20)$. Many participants said that their own relational needs could not be met by 
a single partner $(n=11)$, that they would not want to be the only person meeting their partners' needs $(n=5)$, or that they disliked the general idea of one person trying to meet all of another person's relational needs $(n=10)$. (Four participants made statements fitting into two of these elements and one participant made statements fitting into all three.)

...going back to the historical issues of monogamy, I don't want to feel like I have to fulfill everything for this one person forever. And so I don't want to put that pressure on somebody, and I don't want to feel like that's put on me... (14)

I mean now, (number of) years in, I'm like, please, partners, get emotional support and intimacy from a diversity of people. That sounds wonderful. That sounds like me not having to do all the work. And also me not, I mean, I don't have all the answers. I'm not all those people, I can't provide every possible dimension of emotional intimacy that you might want. Why would we try? That seems absurd. And yet that's a very popular contemporary concept with a lot of traction. (32)

4. Desire for sexual experiences incompatible with monogamy $(n=18)$. Some participants described a desire for frequent or varied sexual experiences $(n=8)$ or for particular kinds of sexual experiences (i.e., kinks, group sexual experiences, or experiences with individuals of different genders; $n=8$ ) that would be difficult or impossible within a monogamous relationship. Three participants described similar things in other CNM people they know; one of these is also included in one of the above elements.

I like the, I think a lot of times sex fades in a relationship. I like the idea of being able to not just have one, sex with one person. And that person not just having sex with me. It just kind of makes you really excited to be with that person, I think. Yeah, doesn't feel like a monotony that you're trying to avoid or settle with. (47)

...I would say to (partner)... you wouldn't really want me monogamous, you know what I mean? There's a lot of stress when somebody's got a higher libido than you do, you know... once it gets to the point where like, ok I have had enough today. Well I haven't, well somebody's giving up, somebody's, you know, somebody's biting their tongue or somebody's putting up with something, and who wants to make love to somebody who's doing you a favor, you know? So it's like, I got some more here. You're busy? I'll go over here and do something, you know what I mean? (33)

5. A preference for autonomy for self and others $(n=29)$. Some participants expressed a desire for personal autonomy in the form of freedom from external control over the ways they relate to others $(n=19)$ and others talked about a desire for autonomy in the form of not wanting to get too deeply enmeshed with any one partner $(n=4)$; a few described both of these elements $(n=3)$. Some participants described a similar distaste for controlling others' behavior or a more general discomfort with the idea of control or "ownership" in relationships $(n=11)$. (Eight participants made statements fitting into elements of both personal autonomy and distaste for controlling others.)

(Interviewer: ... what do you like about nonmonogamy, and what do you get out of it?) Hm, I think both, an answer to both of those is like, freedom. I think it's in lots of different directions, I think it's freedom of expression, to, you know, express those feelings of love or affection if I develop them for people, and they are of a sexual nature, in ways that I don't, that certainly wouldn't be ok with monogamy... (50)

The thing that first drew me to nonmonogamy was the sense of authenticity and shared growth. I really liked feeling like relationships weren't selfish or based around ownership, and feeling like the, you know, the purpose of relationships was to learn from each other and improve each other, not to control each other.... I think the core thing for me goes back to the not wanting to control another person, I think. Yeah, that for me I think is the most important, giving people the freedom to have authentic feelings and opinions and desires, and not have those artificially constrained by social norms or expectations. (12)

(number) grade was really full-on puberty to me, in my life. And I've always wanted to make what I now know of as erotic contact, but I never wanted to be the girl that went steady, or, I never wanted it to be that big a thing, that I couldn't also be, have time for other connections. (44)

6. Interest in life planning among multiple adults $(n=22)$. Many participants mentioned an interest in life plans involving multiple adults, in the form of a desire for or a history of large-group/communal living arrangements 
$(n=7)$, living with or being "family" with multiple partners and/or with metamours $(n=12)$, or multi-person romantic relationships $(n=8)$ ). (Five participants made statements fitting into two of these elements.)

...I think a lot of us, at least me, and I think I'm not the only one, are like, trying to meet basic human need for tribe.... it's almost like, like I would like to have a family, and a group of people who are like, moving through life together. And the best mechanism I have found in the actual world for that is metamours.... because I don't want to go, like, join a monastery and you know, like there are other systems that do that, but they, I think they're not for me. I like getting laid. (18)

7. Discomfort with the idea of holding up monogamy as an ideal $(n=12)$. Some participants reported having felt suspicious of the assumption that monogamy is an ideal state to strive for, often touched off by early experiences of seeing others failing to conform to it $(n=7)$ but occasionally as a result of thinking about the topic more broadly $(n=3)$. Two participants expressed similar skepticism about the ideal of the "nuclear family."

My (relative) was an "other woman" in long-term relationships with married men.... and I was just like, the system doesn't work. And these are people that I know and people that I care about and people that I love, and if good people are doing this thing that I was always taught was bad and wrong, then maybe the system is broken, and maybe it's not that all of these people are evil and terrible, but maybe monogamy doesn't work. So I was interested in another way, and if people are going to like each other outside of their relational agreements, maybe we could have different relational agreements... (26)

(in young adulthood) I read a lot of things. I read a lot of, or at least at the time I read a lot of philosophy, including existentialism. And I think that I, as I learned about romance myth especially, I really started going down a rabbit hole of like, well wait a minute, like why do we have, why do we make all these assumptions anyway? (04)

8. Identifying as LGBTQ2S + . Some LGBTQ2S + participants explicitly linked their interest in CNM to their sexual orientation or gender identity $(n=9)$. Additionally, $78.4 \%(n=40)$ of the current sample identified as something other than heterosexual, and 54.9\% $(n=28)$ identified as something other than cisgendered. This is of course a convenience sample and not in any way representative, but these results do indicate that it is easy to find individuals who share both queer and CNM practices/identities, and that some of them experience the two as being related.

...it's nice to kind of feel like, oh just because I'm in a relationship or like married to someone who's of a particular gender identity, then that's it, like oh I can only ever $\mathrm{f}^{*} \mathrm{ck}$ this person now. I'm still queer, but can't do anything about it... (16)

I was also, felt very, well I mean, pansexual didn't exist, I felt, I guess, just very bisexual, and so that didn't seem to fit in with the monogamous structure, so I needed to figure that out. And then also I felt very androgynous.... And so I didn't seem to fit in with any of the, any of these, you know, expectations, social and cultural expectations that I grew up with in the (country) here. (14)

(Interviewer: ... what do you like about nonmonogamy, and what do you get out of it?) ....I think it's kind of helped me figure out like gender and ways in which that's different for me with different people, and has given me opportunities to meet people who, you know, and form connections that let me explore that, that I wouldn't have done if I was only staying with one person for the whole time. (50)

9. Exposure to community norms that do not assume monogamy $(n=19)$. Some participants mentioned being members of sex-positive, kink, and/or queer communities $(n=8)$, communities with non-Eurocentric or anticolonial stances $(n=4)$, or other communities in which $\mathrm{CNM}$ had become common and accepted $(n=4)$. Others mentioned having had parents who were (or, in one case, openly wanted to be) CNM $(n=5)$. (Two participants made statements fitting into two of these elements.)

It wasn't like I opened up a monogamous relationship or anything. I just like, left college and moved into a culture where monogamy wasn't a thing that anybody was doing.... when I got like kinky and queer, nonmonogamy kind of came with that territory. Yeah, when I got like kinky, queer, and slutty. That sort of all went together. (Interviewer: And you found that to be really normative in the communities you were in.) Absolutely, yeah. (18) ...I did a whole bunch of research and I found out that before colonization, you know, before the European invasion of my people, polyamory was actually a more 
common form of relationship than monogamy.... So that's how I really really got into the polyamorous kind of identity.... So I think when we think about polyamory and monogamy, we're used to thinking (about) it from a Western, European context... as opposed to a decolonized, (ethnicity) context where it's like, it's a way of being, it's a life, you know, it's a way of raising kids, it's a way of forming our society, it's an integral part of who we are. (48)

(Interviewer: So the first question here is just briefly I' $m$ interested in how you came to be nonmonogamous.) Yeah, I, that's weird, like I feel like I came up in a community of people where that was more common, or expected, than not. And it was just sort of like, oh yeah, like this makes, like it just made sense to me in terms of how I viewed sexuality and my attraction to people. And so I think I sort of just stumbled upon it and was like, oh, that works for me. (15)

\section{Summary Regarding Participants Represented in Theme 2}

Overall, $13.7 \%$ of participants appear in one of these subthemes, $19.6 \%$ appear in two, 33.3\% appear in three, $17.7 \%$ appear in four, $13.7 \%$ appear in five or more, and one participant $(2 \%)$ does not appear at all. (Each participant is counted only once per sub-theme, even when they make statements appearing in more than one element within that sub-theme.) The one participant who does not appear in theme 2 was also among those who did not appear in theme $1 .^{2}$ The remaining two who did not appear in theme 1 do appear in theme 2 three and four times, respectively. Thus, a substantial portion of our participants are well-represented by this theme: many

\footnotetext{
2 The self-perceptions of this participant, as a "negative case" (Bazeley, 2009 , p. 12), may be informative as a counterpoint to the self-perceptions of the majority of this study's participants. We provide two quotes from this participant that we find illuminating: "(Interviewer: What do you like about nonmonogamy, what do you get out of it?) Oh I get absolutely nothing, which is partly why we're not doing it anymore. It's just, it's a logistical nightmare and there's been a lot of heartbreak and I think that one more heartbreak like that, then I'm just not gonna be able to crawl my way out of it. So I'm quite done, I think, at least for now.... (but) I really loved and connected deeply with the people that I was with. And that was meaningful and lovely." And "(Interviewer: Yeah, so it's like, you don't stop, you haven't stopped feeling like attractions to people. You're just not interested in.) No, I think it's part of the human experience. I just, or maybe I'm, I don't know, because I know that there are some people who feel that they're wired poly. Like that they were born. I honestly don't know, in the same way that I also really find myself not feeling that sexuality is immutable. I'm just like, you know, maybe some people are very very kind of, very wired to one way or another. Maybe if there's a Kinsey scale for polyamory, then I'm a 3, the same way that I am in my sexuality. Like you know, throw me into the right circumstances and I'll give it a shot, but it doesn't have to be like that, kind of like take it or leave it...".
}

of them experience broad attractions, do not experience their relationships as categorically distinct, do not feel that one person can meet all of another's needs, desire sexual experiences incompatible with monogamy, have a preference for personal autonomy, are drawn to multiple-adult life planning, do not look to monogamy as an ideal, identify on the LGBTQ2S + spectrum, and/or have been exposed to communities with norms that are accepting of nonmonogamy.

\section{Discussion}

Our results suggest that for some individuals, the desire for CNM relationships may be so strong as to be their only viable way of engaging in intimate relationships, as demonstrated in their descriptions of this desire and in their life choices. Many of our participants explicitly describe their interest in CNM as being strong, unchangeable, and/or enduring over time. And they often report having engaged in CNM starting with their earliest dating experiences, whether or not they had encountered any examples of it to emulate, and having deviated from it rarely if at all. Those who did start out dating monogamously report having disliked it, having struggled to conform to it or sometimes even to understand it, or having felt nonmonogamous desires that they did not act on; and when these individuals did later encounter the idea of CNM, they often report having felt immediately drawn to it. Moreover, these individuals' interest in CNM was unchanged regardless of having sometimes experienced or observed unsuccessful or even unethical nonmonogamous situations. Given such a strong and enduring desire for CNM, such individuals would very likely benefit from efforts to reduce stigma against CNM as a relationship practice.

We also note that our sample includes some who report having been comfortable within both CNM and monogamous relationships at various points in their lives. Some of these individuals explicitly reported that for them, a desire for CNM is internally experienced as changeable, or as a choice and not an identity. Two individuals even reported being happily monogamous at the time of the interview, after extensive past experience in CNM relationships. Wood et al. (2021) and St. Vil et al. (2021) both similarly describe some individuals who state that CNM is their most "natural" or even their only viable relationship choice, alongside others who report finding CNM to be practical given their current life circumstances. Other theoretical and empirical work has also suggested that preference for CNM versus monogamy should not be seen as a binary pair of fixed and mutually exclusive opposites (e.g., see Ferrer, 2018; Robinson, 2013). Indeed, it has been suggested that such preference might be most usefully described as existing on a spectrum, perhaps something like the Kinsey scale for sexual orientation (e.g., 
Le Cunff, 2018). Le Cunff (2018) even created a brief selfreport scale based on this idea, though it does not appear to have been widely noted or used thus far.

We also explored a set of characteristics and experiences (theme 2) that appeared often among our participants, and which, we speculate, might predispose a person toward an interest in CNM. Some of these are straightforward and not surprising, in particular reports of feeling frequent attractions to others and desiring sexual experiences that are not possible within monogamy, and these are to some extent echoed in other work finding that interest in CNM is related to greater openness to casual sex (Ka et al., 2020) and that one motivation for engaging in $\mathrm{CNM}$ is the desire for sexual variety and exploration (Cohen, 2015; Moors et al., 2017a; St. Vil et al., 2021; Wood et al., 2021). A strong desire for personal autonomy, a dislike of the idea of one person meeting all of another person's relational needs, and feeling suspicious of monogamy as an ideal state are similarly straightforward, and these line up closely with some of the major motivations for interest or engagement in CNM that have been reported elsewhere: the pursuit of autonomy in relationship choices and diversity in one's sources of needfulfillment (Cohen, 2015; Moors et al., 2017a; Wood et al., 2021) and rejection of monogamous ideals (Sizemore \& Olmstead, 2018).

Two of our sub-themes were more novel: not experiencing (or strongly disliking) categorical distinctions among close relationships, and desiring to organize one's life in collaboration with multiple other adults (e.g., via communal living or multi-partner relationships). We speculate that these characteristics in particular may be associated with a strong and persistent desire for CNM; an individual who does not experience strong distinctions between their relationships (e.g., feels sexual interest in or partnership feelings toward a wide range of their close social contacts), and who has a desire for living arrangements or life plans involving multiple other adults, might be especially likely to feel drawn to CNM relationships.

And finally, one of the sub-themes in theme 2 describes exposure to communities whose norms do not assume monogamy. Although many participants reported having "invented" CNM as young adults, others did not actually engage in it until they became aware of others doing it. Such exposure has also been highlighted as important by Aviram (2010) and indeed has been explicitly labeled the "polyamorous possibility" by Sheff $(2013,2020)$. This exposure might be particularly important for individuals who have some level of comfort with monogamy. These individuals might otherwise continue to attempt only monogamous relationships while feeling secretly different or even as though they were failing in their relationships, unaware that there are other options, perhaps akin to a person with bisexual/ pansexual attractions who lives in a very heteronormative environment. Such a finding points toward the importance of wider visibility of CNM as an option, and suggests that with wider visibility might come greater numbers of individuals engaging in CNM.

It is not hard to imagine why a person who has many of the preferences, feelings, and experiences we have outlined would feel drawn toward nonmonogamy. However, two important questions arise from these findings: the extent to which these characteristics occur individually or instead tend to co-occur as a suite of traits, and whether the number or strength of such characteristics relates to the strength of desire for CNM. Our sample was not recruited with either of these questions in mind. Although our sample includes some individuals who have been comfortable with monogamous relationships at some point in their lives, we did not systematically measure the strength of desire for CNM, and we are also unable to report on the presence or absence of these characteristics among those who strongly desire monogamy. It would be informative to attempt to operationalize the strength of desire for CNM according to some set of variables; to recruit a sample including equal numbers of individuals with a strong desire for CNM, individuals with a strong desire for monogamy, and individuals who have been comfortable with both; and then to examine the co-occurrence of various characteristics and motivations as they relate to the strength of desire for CNM. If such traits tend to be increasingly present in clusters among those with stronger desires for CNM, this would support the idea that there exists a set of characteristics and experiences that form a base on which the desire for CNM rests, providing an important foundation for efforts to combat stigma against this practice.

Such an understanding would also add more nuance to the question of whether a strong desire for CNM should be considered something like an "orientation." It has been argued that one of the pitfalls of using this term to describe a strong desire for CNM is that it could lead to a rigid conceptualization of CNM individuals as immutably and innately different from monogamous individuals, resulting in exclusion (from legal protection, or from communities) of those whose practices or desires vary over time (Aviram, 2010; Heckert, 2010; Klesse, 2014; Tweedy, 2011). Such considerations make it particularly important to explore the existence, experiences, and self-perceptions of individuals with flexible or changeable desires regarding monogamy versus CNM. Exploring the idea that such preferences exist on a spectrum, that desire for monogamy is included on that spectrum, and that these preferences are informed and influenced by a broad set of underlying traits and experiences, could help to push the broader cultural narrative away from oversimplified, rigid, essentialist, or exclusionary ways of understanding those who engage in CNM, while also making space for the understanding that some individuals do have a very strong and persistent desire for CNM relationships. 
Relatedly, we note that this convenience sample included a large proportion of LGBTQ2S + participants. Studies with larger and more representative samples have reliably found an association between CNM and identification as LGBTQ2S + (Balzarini et al., 2018a; Haupert et al., 2017; Levine et al., 2018; Moors et al., 2021; Rubin et al., 2014; St. Vil et al., 2021). Our results point toward some possible reasons for this association, including a desire for sexual and romantic connections with individuals of multiple genders (a finding also echoed by St. Vil et al., 2021; Wood et al., 2021), an exposure to the possibility of CNM via queer and sex-positive communities (a possibility also supported by Moors et al.'s 2021 finding that LGBTQ + individuals were twice as likely as heterosexual ones to know someone who practices $\mathrm{CNM}$ ), and perhaps a more general sense of already not "belonging" within the norms of straight and monogamous culture (an idea also discussed by, e.g., Moors et al., 2017b). There is also the possibility that engaging in CNM and CNM-affirming communities may lead individuals toward exploration of non-heterosexual attractions, and such a mechanism could be one factor underlying the very small number of participants in the current study who identified as completely heterosexual, and the larger number who identified as bisexual, pansexual, "heteroflexible," and the like (see Rubin et al., 2014, for more in-depth discussion of such a possibility). Thus, there may be a complex set of underlying mechanisms in the association between CNM and sexual orientation. Again, exploring such associations could help to paint a three-dimensional portrait of those whose desires fall all along the monogamy-CNM spectrum.

Finally, we note some important limitations of the current study. First, as we have discussed, the findings presented in this paper were discovered fortuitously; we did not set out with the intention of examining these themes. Therefore, we did not recruit a sample that was in some way defined as having a strong desire for CNM, nor did we systematically ask participants about the strength of their desire for CNM. We feel that the fact that so many of our participants did spontaneously describe their desire for CNM in the ways we have laid out, despite not having been explicitly asked, is striking and noteworthy. However, as we have described, recruiting a sample with the explicit intention of further exploring the strength of desire for CNM would be an important step in verifying and extending our observations. Second, because we were interested in individuals' experiences with metamours, our recruitment focused on such experience and we did not systematically ask participants how they would label or describe the "type" of CNM they practice (e.g., polyamory or relationship anarchy, etc.). For this reason, the generalizability of our findings is somewhat unclear, although we do note that all of our participants had engaged in multiple concurrent, ongoing romantic and sexual relationships, and that none identified as swingers. And third, recruiting a sample of participants who have experience interacting with metamours may have biased our results in various ways. For example, our sample does not well represent individuals who practice CNM but prefer not to interact with or have been prevented from interacting with metamours, nor does it represent individuals who are new enough to CNM that they have not yet had significant interactions with metamours (which may, as one outcome, have prevented the inclusion of very young adults). It is possible that such individuals would have different and unanticipated kinds of self-perceptions or observations to share.

\section{Policy Implications}

Our results suggest that for some individuals, a desire for $\mathrm{CNM}$ emerges early in life, remains consistent, and endures despite widespread social stigma and institutionalized disadvantage. These individuals would likely be unhappy in, or perhaps even functionally incapable of, monogamy, and therefore would likely benefit from efforts to reduce the stigma and disadvantage against this relationship practice. Indeed, there may be individuals whose desire for CNM matches this description, who nevertheless do not engage in CNM because they are either unaware of the possibility or fear the effects of (or perhaps have even internalized) this stigma. Such individuals might benefit greatly from stigmareduction efforts. Our results also suggest that some individuals can be comfortable with both CNM and monogamy, and such individuals would likely also benefit from reduction of stigma against CNM, along with increasing visibility of the "polyamorous possibility" (Sheff, 2013, 2020), because this might provide them with more accessible avenues toward exploration of various relationship options. Finally, the overlap between LGBTQ2S + identification and desire for CNM is particularly noteworthy, because it suggests that stigma against CNM may be resulting in compounded marginalization of many already-marginalized LGBTQ2S + individuals.

Further, our results regarding the characteristics and experiences common to those who practice CNM (theme 2 ), in concert with similar findings in other recent investigations, begin to paint a portrait of CNM as a phenomenon aligned with a stable and predictable set of motivations and personal characteristics. However, we note that, although it is of interest to investigate the possible traits and experiences underlying a desire for CNM, as we have done, the argument that those who practice CNM should be free from stigma and disadvantage is not dependent on how their preference arises or how it is defined.

Social stigma and institutionalized disadvantage are interrelated (Hatzenbuehler, 2016), and thus approaches toward their reduction are intertwined. Important efforts include education and outreach aimed at doctors, 
therapists, and other health service providers, along with researchers and other social scientists working in the field of intimate relationships; increased inclusiveness toward multiple partnerships by community-based organizations, particularly those that serve LGBTQ2S + individuals; and promotion of positive media portrayals of CNM. The American Psychological Association's Committee on Consensual Nonmonogamy, first launched as a task force in 2018 , is currently engaged in efforts to support scholars and clinicians working to advance CNM visibility and acceptance on these fronts.

And finally, efforts to achieve legal recognition of multiple concurrent partnerships could go a long way toward reduction of the disadvantages associated with lack of such recognition, well-documented during the struggle for samesex marriage (e.g., Patterson, 2009; Ramos et al., 2009; Riggle et al., 2005; and see Aviram \& Leachman, 2015, for historical perspective and a comparison of struggles for same-sex versus CNM marriage). Such efforts may not be as far-fetched as they seem at the current historical moment; the first ordinance recognizing multiple domestic partnerships in the USA was passed by the city of Somerville, Massachusetts in June of 2020 (Somerville, MA Code of Ordinances, 2020).

Acknowledgements We wish to thank several individuals whose encouragement and thoughtful commentary on various drafts of this work was invaluable: Alina Labrador, Sahil Khanna, Marisa Musso, and Justin Hinojoza. We would also like to thank the APA Committee on Consensual Nonmonogamy for its efforts to encourage work of this kind.

Author Contribution Both authors contributed to the study design and conception. Material preparation and data collection were carried out by the first author. Data analysis was carried out by the first author, with consultation and data auditing by the second author. The first draft of the manuscript was written by the first author, and both authors subsequently revised and commented on versions of the manuscript. Both authors read and approved the final manuscript.

Availability of Data and Material De-identified data (direct quotes from participants) underlying the results of this study are available from the first author on request, subject to minor redaction due to privacy concerns of specific participants.

\section{Declarations}

Conflict of Interest In the future, the first author may use some of the data gathered in the process of this research to create a for-profit, booklength work. The authors declare that they have no other financial or other conflicting interests related to this research or its publication.

Open Access This article is licensed under a Creative Commons Attribution 4.0 International License, which permits use, sharing, adaptation, distribution and reproduction in any medium or format, as long as you give appropriate credit to the original author(s) and the source, provide a link to the Creative Commons licence, and indicate if changes were made. The images or other third party material in this article are included in the article's Creative Commons licence, unless indicated otherwise in a credit line to the material. If material is not included in the article's Creative Commons licence and your intended use is not permitted by statutory regulation or exceeds the permitted use, you will need to obtain permission directly from the copyright holder. To view a copy of this licence, visit http://creativecommons.org/licenses/by/4.0/.

\section{References}

Aviram, H. (2010). Geeks, goddesses, and green eggs: Political mobilization and the cultural locus of the polyamorous community in the San Francisco Bay Area. In M. Barker \& D. Langdridge (Eds.), Understanding non-monogamies (pp. 87-93). Routledge.

Aviram, H., \& Leachman, G. (2015). The future of polyamorous marriage lessons from the marriage equality struggle. Harvard Journal of Law \& Gender, 38, 269-336.

Balzarini, R. N., Dharma, C., Kohut, T., Holmes, B. M., Campbell, L., Lehmiller, J. J., \& Harman, J. J. (2018a). Demographic comparison of American individuals in polyamorous and monogamous relationships. Journal of Sex Research, 18, 1-14.

Balzarini, R. N., Shumlich, E. J., Kohut, T., \& Campbell, L. (2018b). Dimming the halo around monogamy: Re-assessing stigma surrounding consensually non-monogamous romantic relationships as a function of personal relationship orientation. Frontiers in Psychology. https://doi.org/10.3389/fpsyg.2018.00894

Balzarini, R. N., Shumlich, E. J., Kohut, T., \& Campbell, L. (2020). Sexual attitudes, erotophobia, and sociosexual orientation differ based on relationship orientation. The Journal of Sex Research, $57(4), 458-469$.

Barker, M. (2005). This is my partner, and this is my... partner's partner: Constructing a polyamorous identity in a monogamous world. Journal of Constructivist Psychology, 18(1), 75-88.

Barker, M., \& Langdridge, D. (2010). Whatever happened to nonmonogamies? Critical reflections on recent research and theory. Sexualities, 13(6), 748-772.

Barker, M., \& Ritchie, A. (2007). Hot bi babes and feminist families: Polyamorous women speak out. Lesbian and Gay Psychology Review, 8(2), 141-151.

Bazeley, P. (2009). Analysing qualitative data: More than 'identifying themes.' The Malaysian Journal of Qualitative Research, 2(2), 6-22.

Bazeley, P., \& Jackson, K. (2013). Qualitative data analysis with NVivo (2nd ed.). Sage.

Boyd, J. P. E. (2017). Perceptions of polyamory in Canada. Canadian Institute for Law and the Family. http://hdl.handle.net/1880/107212

Braun, V., \& Clarke, V. (2006). Using thematic analysis in psychology. Qualitative Research in Psychology, 3(2), 77-101.

Braun, V., \& Clarke, V. (2021). Can I use TA? Should I use TA? Should I not use TA? Comparing reflexive thematic analysis and other pattern-based qualitative analytic approaches. Counseling Psychotherapy Research, 21, 37-47.

Cohen, M. T. (2015). An exploratory study of individuals in nontraditional, alternative relationships: How open are we? Sexuality \& Culture, 20(2), 295-315.

Conley, T. D., Matsick, J. L., Moors, A. C., \& Ziegler, A. (2017). Investigation of consensually nonmonogamous relationships: Theories, methods, and new directions. Perspectives on Psychological Science, 12(2), 205-232.

Conley, T. D., Moors, A. C., Matsick, J. L., \& Ziegler, A. (2013). The fewer the merrier?: Assessing stigma surrounding consensually non-monogamous romantic relationships. Analyses of Social Issues and Public Policy, 13(1), 1-30. 
Conley, T. D., Moors, A. C., Ziegler, A., \& Karathansis, C. (2012). Unfaithful individuals are less likely to practice safer sex than openly non-monogamous individuals. Journal of Sexual Medicine, 9, 1559-1565.

Corbin, J., \& Strauss, A. (1990). Grounded theory research: Procedures, canons, and evaluative criteria. Zeitschrift Fur Soziologie, 19(6), 418-427.

de Visser, R., \& McDonald, D. (2007). Swings and roundabouts: Management of jealousy in heterosexual 'swinging' couples. British Journal of Social Psychology, 46(2), 459-476.

Ferrer, J. N. (2018). Beyond the non/monogamy system: Fluidity, hybridity, and transcendence in intimate relationships. Psychology \& Sexuality, 9(1), 3-20.

Fairbrother, N., Hart, T. A., \& Fairbrother, M. (2019). Open relationship prevalence, characteristics, and correlates in a nationally representative sample of Canadian adults. The Journal of Sex Research, 56(6), 695-704.

Fleckenstein, J. R. \& Cox, D. W. (2015). The association of an open relationship orientation with health and happiness in a sample of older U.S. adults. Sexual and Relationship Therapy, 30(1), 94-116.

Giorgi, A. (2012). The descriptive phenomenological psychological method. Journal of Phenomenological Psychology, 43(1), 3-12.

Hatzenbuehler, M. L. (2016). Structural stigma and health inequalities: Research evidence and implications for psychological science. American Psychologist, 71(8), 742-751.

Haupert, M. L., Gesselman, A. N., Moors, A. C., Fisher, H. E., \& Garcia, J. R. (2017). Prevalence of experiences with consensual nonmonogamous relationships: Findings from two national samples of single Americans. Journal of Sex \& Marital Therapy, 43(5), 424-440.

Heckert, J. (2010). Love without borders? Intimacy, identity, and the state of compulsory monogamy. In M. Barker \& D. Langdridge (Eds.), Understanding non-monogamies (pp. 255-266). Routledge.

Hutzler, K. T., Giuliano, T. A., Herselman, J. R., \& Johnson, S. M. (2016). Three's a crowd: Public awareness and (mis)perceptions of polyamory. Psychology \& Sexuality, 7(2), 69-87.

Ka, W. L., Bottcher, S., \& Walker, B. R. (2020). Attitudes toward consensual non-monogamy predicted by sociosexual behavior and avoidant attachment. Current Psychology. https://doi.org/10.1007/ s12144-020-00941-8

Klesse, C. (2005). Bisexual women, non-monogamy and differentialist anti-promiscuity. Sexualities, 8(4), 445-464.

Klesse, C. (2011). Notions of love in polyamory-Elements in a discourse on multiple loving. Laboratorium, 3(2), 4-25.

Klesse, C. (2014). Polyamory: Intimate practice identity or sexual orientation? Sexualities, 17(1-2), 81-99.

Le Cunff, A. L. (2018). Non-monogamy: Measuring degrees of sexual and romantic exclusivity in relationships. Available at SSRN: https://doi.org/10.2139/ssrn.3232078

Lehmiller, J. (2015). A comparison of sexual health history and practices among monogamous and consensually nonmonogamous sexual partners. The Journal of Sexual Medicine, 12(10), 2022-2028.

Levine, E. E., Herbenick, D., Martinez, O., Fu, T., \& Dodge, B. (2018). Open relationships, nonconsensual nonmonogamy, and monogamy among U.S. adults: Findings from the 2012 National Survey of Sexual Health and Behavior. Archives of Sexual Behavior, 47, $1439-1450$.

Moors, A. C., Gesselman, A. N., \& Garcia, J. R. (2021). Desire, familiarity, and engagement in polyamory: Results from a national sample of single adults in the United States. Frontiers in Psychology, $12,619-640$

Moors, A. C., Matsick, J. L., \& Schechinger, H. A. (2017a). Unique and shared relationship benefits of consensually non-monogamous and monogamous relationships. European Psychologist, 22, 55-71.
Moors, A. C., Matsick, J. L., Ziegler, A., Rubin, J., \& Conley, T. D. (2013). Stigma toward individuals engaged in consensual nonmonogamy: Robust and worthy of additional research. Analyses of Social Issues and Public Policy, 13(1), 52-69.

Moors, A. C., Selterman, D. F., \& Conley, T. D. (2017b). Personality correlates of desire to engage in consensual non-monogamy among lesbian, gay, and bisexual individuals. Journal of Bisexuality, 17(4), 418-434.

Morrison, T. G., Beaulieu, D., Brockman, M., \& Beaglaoich, C. (2013). A comparison of polyamorous and monoamorous persons: Are there differences in indices of relationship well-being and sociosexuality? Psychology \& Sexuality, 4(1), 75-91.

O'Byrne, P., \& Haines, M. (2019). A qualitative exploratory study of consensual non-monogamy: Sexual scripts, stratifications, and charmed circles. Social Theory \& Health. https://doi.org/10.1057/ s41285-019-00120-1

Parsons, J., Starks, T. J., Gamarel, K. E., \& Grov, C. (2012). Nonmonogamy and sexual relationship quality among same-sex male couples. Journal of Family Psychology, 26(5), 669-677.

Patterson, C. J. (2009). Children of lesbian and gay parents: Psychology, law, and policy. American Psychologist, 64(8), 727-736.

Polkinghorne, D. E. (1989). Phenomenological research methods. In Valle, R. S., \& Halling, S. (Eds.), Existential-phenomenological perspectives in psychology. Exploring the breadth of human experience (pp. 41-60), New York: Plenum.

Ramos, C., Goldberg, N. G., \& Badgett, M. V. L. (2009). The effects of marriage equality in Massachusetts: A survey of the experiences and impact of marriage on same-sex couples. Los Angeles, CA: Williams Institute. Retrieved 28/1/21 from https://escholarship. org/uc/item/9dx6v3kj

Riggle, E. D. B., Thomas, J. D., \& Rostosky, S. S. (2005). The marriage debate and minority stress. Political Science and Politics, $38(2), 221-224$

Ritchie, A. (2010). Discursive constructions of polyamory in mononormative media culture. In M. Barker \& D. Langdridge (Eds.), Understanding non-monogamies (pp. 46-51). Routledge.

Robinson, M. (2013). Polyamory and monogamy as strategic identities. Journal of Bisexuality, 13, 21-38.

Rodrigues, D., Fasoli, F., Huic, A., \& Lopes, D. (2018). Which partners are more human? Monogamy matters more than sexual orientation for dehumanization in three European countries. Sexuality Research and Social Policy, 15(4), 504-515.

Rubel, A., \& Bogaert, A. F. (2015). Consensual nonmonogamy: Psychological well-being and relationship quality correlates. Journal of Sex Research, 52(9), 961-982.

Rubin, J., Moors, A. C., Matsick, J. L., Ziegler, A., \& Conley, T. D. (2014). On the margins: Considering diversity among consensually non-monogamous relationships. Journal Fur Psychologie, $22(1), 1-23$

Saldaña, J. (2013). The coding manual for qualitative researchers. Sage Publications.

Sheff, E. (2013). The polyamorists next door: Inside multiple-partner relationships and families. Rowman \& Littlefield.

Sheff, E. (2016). Resilience in polyamorous families. In Karian, P. (Ed.), Critical \& experimental: Dimensions in gender and sexual diversity, Resonance Publications.

Sheff, E. (2020). Polyamory is deviant-but not for the reasons you may think. Deviant Behavior, 41(7), 882-892.

Sizemore, K. M., \& Olmstead, S. B. (2017). A systematic review of research on attitudes towards and willingness to engage in consensual non-monogamy among emerging adults: Methodological issues considered. Psychology \& Sexuality, 8(1-2), 4-23.

Sizemore, K. M., \& Olmstead, S. B. (2018). Willingness of emerging adults to engage in consensual nonmonogamy: A mixed-methods analysis. Archives of Sexual Behavior, 47, 1423-1438. 
Somerville, MA Code of Ordinances. (2020). Ordinance no. 202016. Accessed 24/1/21 from https://library.municode.com/ma/ somerville/ordinances/code_of_ordinances?nodeId $=1028806$

St. Vil, N., Leblanc, N. M., \& Giles, K. N. (2021). The who and why of consensual nonmonogamy among African Americans. Archives of Sexual Behavior, 50, 1143-1150.

Tweedy, A. (2011). Polyamory as a sexual orientation. University of Cincinnati Law Review, 79(4), Article 5.

Willey, A. (2010). 'Science says she's gotta have it': Reading for racial resonances in woman-centered poly literature. In M. Barker \& D.
Langdridge (Eds.), Understanding non-monogamies (pp. 34-45). Routledge.

Wood, J., Santis, R., De Milhausen., Desmarais, R. S. (2021) Motivations for engaging in consensually non-monogamous relationships. Archives of Sexual Behavior. https://doi.org/10.1007/ s10508-020-01873-x

Publisher's Note Springer Nature remains neutral with regard to jurisdictional claims in published maps and institutional affiliations. 